\title{
Development, Validity and Reliability of the Londrina Activities of Daily Living Protocol for Subjects With COPD
}

\author{
Thaís Sant'Anna PhD, Leila Donária MSc, Karina C Furlanetto MSc, Fernanda Morakami MSc, \\ Antenor Rodrigues MSc, Talita Grosskreutz PT, Nidia A Hernandes PhD, Rik Gosselink PhD, and \\ Fabio Pitta PhD
}

\begin{abstract}
BACKGROUND: To avoid symptoms, patients with COPD may reduce the amount of activities of daily living (ADL). Therefore, the aim of the present study was to develop a standardized protocol to evaluate ADL performance in subjects with COPD (Londrina ADL protocol) and to assess the validity and reliability of the protocol in this population. METHODS: The Londrina ADL protocol was created based on activities included in previous studies aimed at investigating outcomes from ADL. Activities were included in the protocol because they could represent other activities of similar patterns and because they could be actually performed, not simulated. Twenty subjects with COPD (12 men, $70 \pm 7$ y old, $\mathrm{FEV}_{1}=54 \pm 15 \%$ predicted) wore 2 motion sensors while performing the protocol 4 times, 2 of them wearing a portable gas analyzer. Subjects were also submitted to assessments of lung function, functional exercise capacity, functional status, impact on health status, and physical activity in daily life. RESULTS: The Londrina ADL protocol comprised of 5 activities representing ADL, involving upper limbs, lower limbs, and trunk movements. Londrina ADL protocol duration presented high values of intraclass correlation coefficient, even using a mask for gas analysis (intraclass correlation coefficient $>0.90, P<.001$ ). Intensity of movement during the protocol performance was highly correlated to intensity of movement in daily life $(r=0.71)$. The protocol duration was correlated with functional status and impact on health status variables from questionnaires $(0.36 \leq \mathrm{r} \leq \mathbf{0 . 5 9})$. There was also correlation between functional exercise capacity and the protocol duration $(\mathrm{r}=-\mathbf{0 . 6 4})$. CONCLUSIONS: The Londrina ADL protocol was a valid and reliable protocol to evaluate ADL performance in subjects with COPD. It is a protocol that can be used in clinical practice and in future studies to investigate ADL outcomes, including those studies that require gas analysis and the wearing of a mask. Key words: COPD; activities of daily living; aging; motor activity; chronic limitation of activity; symptoms and signs. [Respir Care 2017;62(3):288-297. (C) 2017 Daedalus Enterprises]
\end{abstract}

\section{Introduction}

Dyspnea and fatigue are the most common symptoms reported by patients with $\mathrm{COPD},{ }^{1}$ a progressive disease

\footnotetext{
Dr Sant'Anna, Ms Donária, Ms Furlanetto, Ms Morakami, Mr Rodrigues, Ms Grosskreutz, Dr Hernandes, and Dr Pitta are affiliated with the Laboratory of Research in Respiratory Physiotherapy, Department of Physiotherapy, State University of Londrina, Londrina, Brazil. Dr Gosselink is affiliated with the Respiratory Division and Pulmonary Rehabilitation, University Hospital Gasthuisberg, Katholieke Universiteit Leuven, Leuven, Belgium.

This work was supported by the Conselho Nacional de Desenvolvimento Científico e Tecnológico $(\mathrm{CNPq})$, Brazil. The authors have disclosed no conflicts of interest.
}

with pulmonary and extrapulmonary manifestations. ${ }^{2}$ Therefore, patients involve themselves in a negative spiral, reducing participation in physical activities, intending to avoid symptoms. ${ }^{3}$ However, the less they perform physical activities, the more they worsen their physical conditioning and symptoms. ${ }^{4}$ This vicious cycle affects even simple features, such as activities of daily living (ADL). ${ }^{4}$

\footnotetext{
Correspondence: Fabio Pitta $\mathrm{PhD}$, Departamento de Fisioterapia, Universidade Estadual de Londrina, Avenida Robert Koch, 60-Vila Operária, 86038-350-Londrina, Paraná, Brazil. E-mail: fabiopitta@uol.com.br.
}

DOI: $10.4187 /$ respcare.05058 


\section{Londrina ADL Protocol in SubJects With COPD}

ADL are activities related to the subject's routine and are generally linked to domestic tasks, personal care, leisure, and work-related activities. As a consequence of increased symptoms, patients reduce the amount of ADL, leading to a reduction in quality of life, which is associated with limitations to perform ADL. ${ }^{5}$ Considering the impact of a limited ADL performance on the daily life of patients with COPD, the adequate evaluation of ADL performance is relevant for clinical practice in this population.

A term often used to describe the level of ADL impairment and performance is "functional status."6 The most common instruments available to evaluate ADL and functional status are questionnaires. Some examples of questionnaires in widespread use for these purposes, validated for use in patients with COPD, are the pulmonary functional status and dyspnea questionnaire, modified version (PFSDQ-M $)^{7,8}$ and the London chest activity of daily living questionnaire (LCADL). ${ }^{9,10}$ In these questionnaires, patients report to which degree symptoms interfere on their ADL performance. Although it is very important to know how patients perceive their own ADL performance and limitations, an objective assessment of this outcome can provide complementary information.

The Glittre ADL test is a protocol developed to assess functional status in patients with COPD. For this, patients have to perform 4 different activities (rising up from sitting position, walking, moving up and down an interposed 2-step staircase, and organizing objects on shelves) through a $10-\mathrm{m}$ corridor, going back and forth 5 times along the corridor. The protocol has to be performed as fast as possible, and the time spent to complete it is the test's main outcome. ${ }^{11}$ However, the Glittre ADL test does not include an in-depth and objective assessment of problematic activities involving the upper limbs, which are often limited in patients with COPD. ${ }^{12}$ Furthermore, it was shown that the Glittre ADL test induces a higher oxygen uptake than the 6-min walk test (6MWT), ${ }^{13}$ an exercise capacity test. Moreover, since the Glittre ADL test is performed as fast as possible and not at the usual ADL pace, it correlates more strongly with the 6MWT (a test in which the instruction is to walk as far as possible in $6 \mathrm{~min}$ ) than with functional status questionnaires. ${ }^{11}$ Since it is known that the 6MWT frequently makes patients with COPD achieve their near-maximal sustainable intensity during the test, ${ }^{14}$ it is questionable to associate the Glittre ADL test with a real-life ADL representation; instead, it should more likely be associated with a test of functional exercise capacity.

In an Asian study, ${ }^{15}$ the psychometric properties of an ADL protocol, the monitored functional task evaluation, were investigated in subjects with COPD. However, this protocol is described as "symptom-limited," since the effort intensity during performance of activities is monitored and limited to $70 \%$ of maximum heart rate. ${ }^{15}$ Therefore, the monitored functional task evaluation jeopardizes the

\section{QUICK LOOK}

\section{Current knowledge}

Dyspnea and fatigue are the most common symptoms reported by patients with COPD. As a consequence of increased symptoms, patients reduce the amount of activities of daily living (ADL). Considering the impact of a limited ADL performance on the daily life of patients with COPD, it is relevant for clinical practice to be able to evaluate ADL performance in a standardized way in this population.

\section{What this paper contributes to our knowledge}

The Londrina ADL protocol was shown to be a valid and reliable test, even when subjects were using a mask for gas analysis. It is a protocol that can be used in clinical practice and in scientific studies to investigate ADL outcomes, including those studies that require gas analysis and the wearing of a mask. Therefore, by creating the Londrina ADL protocol and investigating its validity and reliability, the present study contributes the possibility of having a standardized method for assessment of ADL performance in subjects with COPD.

possibility of investigating the real performance of patients, since they will not freely execute the activities as they do in daily life but will rather perform them according to the limit imposed by the protocol.

Another gap in the literature is that when researchers want to investigate any outcome coming from or associated with ADL (eg, dynamic hyperinflation, $\mathrm{S}_{\mathrm{pO}_{2}}$, or energy expenditure), it is common to create their own ADL protocols specifically for their studies. ${ }^{16-22}$ This leads to a lack of standardization in the objective assessment of ADL in patients with COPD. Furthermore, almost all of these protocols did not have their psychometric properties evaluated. Obviously, this is a scenario that imposes a methodological bias in scientific investigations, hindering comparisons between different studies.

Considering the limitations in the assessment of ADL performance in patients with COPD identified in the literature, the development of a laboratory-based protocol that in fact reflects ADL performed at the patients' usual speed, which is reliable and objectively assesses ADL performance, would be useful to standardize the assessment of ADL performance and contribute to the in-depth evaluation of patients with COPD. For these reasons, we propose a new protocol of objective ADL assessment in subjects with COPD, which is intended to counteract the disadvantages of the available tools: the Londrina ADL protocol. After creating the protocol, the present study 


\section{Londrina ADL Protocol in SubJects With COPD}

Table 1. Activities Included in Activities of Daily Living Protocols of Previous Studies

\begin{tabular}{|c|c|c|}
\hline Authors & Year & Activities of Daily Living Included \\
\hline Fong et $\mathrm{al}^{15}$ & 2001 & $\begin{array}{l}\text { Walking on level ground for a fixed distance; standing up from a chair and then sitting down; lifting a 3-kg } \\
\text { weight load from waist level to a higher level and then returning the weight back to waist level; walking } \\
\text { on level ground for a fixed distance while carrying in each hand a load of } 3 \mathrm{~kg} \text {; rising up and down on a } \\
\text { step. }\end{array}$ \\
\hline Velloso et $\mathrm{al}^{21}$ & 2003 & $\begin{array}{l}\text { Sweeping the floor; erasing a blackboard; lifting pots weighing } 0.5,1.0,2.0,3.0,4.0 \text {, and } 5.0 \mathrm{~kg} \text { from waist } \\
\text { level to above the head and putting them down again on a surface at that level; screwing in and out a } \\
\text { bulb from sockets placed at the height of the eyes. }\end{array}$ \\
\hline Skumlien et al ${ }^{11}$ & 2005 & $\begin{array}{l}\text { Rising from a seated position; walking; moving up and down an interposed 2-step staircase; repositioning } \\
\text { cartons weighing } 1 \mathrm{~kg} \text { in shelves. All activities were performed by subjects carrying a backpack } \\
\text { containing } 2.5 \mathrm{~kg} \text { (women) or } 5.0 \mathrm{~kg} \text { (men). }\end{array}$ \\
\hline Hill et $\mathrm{al}^{23}$ & 2008 & $\begin{array}{l}\text { Standing up from a chair and carrying } 2 \text { grocery bags, each filled with } 10 \text { items }(410 \mathrm{~g} \text { each) to a bench, } \\
\text { before stacking the items onto a shelf } 15 \mathrm{~cm} \text { above shoulder height. }\end{array}$ \\
\hline Lahaije et al ${ }^{24}$ & 2010 & $\begin{array}{l}\text { Vacuum cleaning; carrying weight during walking ( } 4-5 \mathrm{~kg} \text { ); showering; putting on socks and shoes; getting } \\
\text { dressed; (un)loading washing machine; climbing stairs; dish washing; hanging up laundry; window } \\
\text { cleaning; wiping terrace/cleaning floor; cleaning cupboard; gardening; peeling potatoes. }\end{array}$ \\
\hline Sant'Anna et al ${ }^{19}$ & 2012 & $\begin{array}{l}\text { Sitting on a chair and rising; climbing up and down a step; lying down on a bed and then rising; dressing } \\
\text { and removing a shirt. }\end{array}$ \\
\hline Pessoa et $\mathrm{al}^{25}$ & 2012 & $\begin{array}{l}\text { Picking up weights of } 0.5,1,2,3,4 \text {, and } 5 \mathrm{~kg} \text { from a waist-high surface and positioning them on a shelf } \\
\text { located above the head. }\end{array}$ \\
\hline Vaes et $\mathrm{al}^{26}$ & 2012 & $\begin{array}{l}\text { Putting on } 2 \text { socks (sitting in chair), } 2 \text { shoes (sitting in chair), and a vest (standing); folding } 8 \text { towels } \\
\text { (standing); putting away groceries ( } 6 \text { cans of beans of } 400 \mathrm{~g} \text { each) in a cupboard (standing and walking); } \\
\text { washing } 4 \text { dishes, } 4 \text { cups, and } 4 \text { saucers (standing); sweeping the floor. }\end{array}$ \\
\hline Castro et $\mathrm{al}^{27}$ & 2012 & Walking up and down stairs and up and down a ramp; sweeping and mopping. \\
\hline Lahaije et al ${ }^{18}$ & 2013 & $\begin{array}{l}\text { Vacuum cleaning; sweeping floor; stair climbing; carrying bags; changing beds; dish washing; window } \\
\text { cleaning; hanging laundry; digging garden; putting on shoes; cleaning cupboards; walking with the dog; } \\
\text { emptying dishwasher. }\end{array}$ \\
\hline Castro et $\mathrm{al}^{17}$ & 2013 & $\begin{array}{l}\text { Brushing teeth; washing face; combing hair; simulating bathing; putting on and taking off clothes and } \\
\text { shoes; sweeping the floor; storing pots weighting } 1.5 \mathrm{~kg} \text { in upper and lower shelves; washing dishes; } \\
\text { writing on a sheet of paper; answering the phone without any arm support; opening and closing drawers; } \\
\text { moving paper sheets from one side to the other of a desk; walking up and down a flight of stairs; } \\
\text { walking up and down a ramp; walking along a } 25 \text {-m corridor carrying } 2.5 \mathrm{~kg} \text { in both hands and } 5.0 \mathrm{~kg} \text { in } \\
\text { one hand for another. }\end{array}$ \\
\hline Velloso et al ${ }^{28}$ & 2013 & $\begin{array}{l}\text { Teeth brushing; face washing; hair combing; taking shirt off; putting shirt on; putting shoes on; taking } \\
\text { shoes off; shaving for men; waxing for women. }\end{array}$ \\
\hline Rutten et $\mathrm{al}^{29}$ & 2014 & $\begin{array}{l}\text { Putting on shoes, socks, and a coat; folding up } 16 \text { towels and placing them in a basket; placing } 12 \text { cans } \\
(400 \mathrm{~g}) \text { in a shopping basket; washing } 8 \text { plates, } 8 \text { cups, and } 8 \text { saucers and placing them in a plate rack; } \\
\text { sweeping plastic blocks with a broom. }\end{array}$ \\
\hline Barusso et $\mathrm{al}^{30}$ & 2015 & $\begin{array}{l}\text { Getting out of bed; putting on shoes; making the bed; showering; lifting and lowering containers on a shelf } \\
\text { above the shoulder girdle; and raising and lowering pots on a shelf below the pelvic girdle. }\end{array}$ \\
\hline Silva et al ${ }^{16}$ & 2015 & $\begin{array}{l}\text { Walking down a corridor carrying a bag weighing } 5 \mathrm{~kg} \text {; going up and down a } 10 \text {-step staircase; walking on } \\
\text { a treadmill with } 5 \% \text { inclination; putting shoes on and taking them off; lifting pots }(1,2 \text {, and } 3 \mathrm{~kg} \text { ) from a } \\
\text { table to the highest position over the subject's head, using both arms, and then bringing the pots back to } \\
\text { the table; simulating taking a shower. }\end{array}$ \\
\hline
\end{tabular}

then investigated the validity and reliability of the new protocol in this population.

\section{Methods}

For the development of a new protocol for the assessment of ADL performance in subjects with COPD, bibliographic research was done to find studies that applied different ADL protocols in this population. Based on these studies, the ADL included in those protocols were registered, and the most prevalent ADL were verified. Table 1 shows these studies and the ADL included in each one. After that, meetings with the authors of the present study were undertaken to discuss the ADL included in the previous studies. Those meetings had the objective of determining the activities that should be prioritized for inclusion in the new ADL protocol. The criteria used to select the activities to be included in the new protocol were: activities that could make the protocol simple and feasible; activities that involved the utilization of upper and lower limbs and trunk flexion/inclination; activities that reproduced what is commonly performed in the day-to-day rou- 


\section{Londrina ADL Protocol in SubJects With COPD}

tines of most people; activities that could be performed in the most realistic way that was possible, avoiding simulations (ie, avoid pretending one is having a shower, sweeping the floor, shaving, etc). It is important to highlight that each activity included in the Londrina ADL protocol does not necessarily represent the intention to evaluate subjects' performance in that specific activity, but also in activities with similar movements to that activity. In other words, when an activity such as hanging clothes on a clothesline was included, the objective was not necessarily to evaluate subject performance only during hanging clothes on a clothesline, since several subjects do not actually perform this activity in daily life. Actually, the objective was to evaluate subjects' performance during an activity that includes upper-limb movement above the head associated with trunk movement in the standing position. Finally, before investigating psychometric properties of the new protocol, we applied it in a sample of young healthy adults and subjects with COPD to identify practical limitations of the protocol and to correct them. The new protocol was named Londrina ADL protocol because it was created in the Laboratory of Research in Respiratory Physiotherapy of the State University of Londrina, Brazil.

For the analysis of the protocol's criterion validity and reliability, 20 subjects with COPD were included. As inclusion criteria, they presented with a diagnosis of COPD according to the Global Initiative for Chronic Obstructive Lung Disease criteria, ${ }^{2}$ clinical stability (at least 3 months without severe exacerbation of the disease), absence of neuromuscular or skeletal disorders that could impair ADL performance, and not having basal $\mathrm{P}_{\mathrm{aO}_{2}}$ and $\mathrm{S}_{\mathrm{pO}_{2}}$ values consistent with an indication of long-term oxygen therapy $\left(\mathrm{P}_{\mathrm{aO}_{2}} \leq 55 \mathrm{~mm} \mathrm{Hg}\right.$ or $\left.\mathrm{S}_{\mathrm{aO}_{2}}<88 \%\right)$. Patients were excluded if they were not able to execute the proposed evaluations. This research was approved by the ethics committee of the State University of Londrina, Brazil (approval 031/2013), and all participants provided informed consent.

Assessments were done at 3 times. On the first visit to the laboratory, subjects had their anthropometric data collected and were submitted to arterial blood gas analysis and assessment of lung function by spirometry, ${ }^{31,32}$ impact on health status by the COPD assessment test, ${ }^{33}$ and functional status by the LCADL $^{9,10}$ and the PFSDQ-M. ${ }^{7,8}$ On the second visit, subjects performed the Londrina ADL protocol 4 times, with sufficient intervals to recover basal $\mathrm{S}_{\mathrm{pO}_{2}}$, heart rate, and perceived effort (modified Borg scale). ${ }^{34}$ Two of these protocol performances occurred with subjects wearing a portable gas analyzer (Oxycon mobile device, CareFusion, San Diego, California), ${ }^{35}$ registering the oxygen consumption $\left(\dot{\mathrm{V}}_{\mathrm{O}_{2}}\right)$. The portable gas analyzer weighs around $1 \mathrm{~kg}$ and requires wearing a face mask. The order of testing (with and without the portable gas analyzer) was randomized. During all protocol performances, $\mathrm{S}_{\mathrm{PO}_{2}}$, heart rate, energy expenditure (SenseWear armband,
Body Media, Pittsburgh, Pennsylvania), ${ }^{36}$ and intensity of movement (DynaPort Move Monitor, McRoberts, Den Haag, The Netherlands) ${ }^{37}$ were registered. Before and after the protocol, dyspnea and fatigue sensation were also assessed by the modified Borg scale. ${ }^{34}$ Each subject was asked to perform each activity at the usual pace at which he/she would perform it in real life, and the main outcome registered from the Londrina ADL protocol was the time spent by subjects to perform the protocol (ie, the Londrina ADL protocol duration), verified using a simple stopwatch. After performing the 4 protocols, subjects reported the degree of difficulty in performing each protocol by a Likert scale. This scale ranged from 0 to 10 , where 0 represents not difficult at all and 10 represents too much difficulty. On the third visit, subjects were submitted to functional exercise capacity evaluation by the 6MWT ${ }^{38}$ and received the 2 activity monitors (SenseWear armband and DynaPort Move Monitor). Subjects wore these devices during 2 consecutive weekdays, $24 \mathrm{~h} / \mathrm{d}$. The main outcomes from the activity monitors were the total energy expenditure by the SenseWear armband and the movement intensity from the DynaPort Move Monitor.

\section{Sample Size Calculation}

The intensity of movement during daily life, an outcome registered objectively by physical activity monitoring, was selected as the main variable to verify the validity of the Londrina ADL protocol as representing subjects' real ADL performance. A sample of 14 subjects would be necessary to find a correlation of at least 0.70 between movement intensity during the Londrina ADL protocol and movement intensity during daily life, considering $\alpha=.05$ and $\beta=0.80$. The calculation was done using BioStat 3.0 software (AnalystSoft, Walnut, California). Although movement intensity was the main outcome to evaluate the protocol's validity, other variables were also included in the study methodology, with the objective to have a more in-depth analysis of the new protocol.

\section{Statistical Analysis}

Data distribution was analyzed by the Shapiro-Wilk test. According to normality in data distribution, data were expressed as mean and SD or median and interquartile range; correlations between outcomes were verified using Pearson or Spearman coefficients; and comparisons were done using a paired Student $t$ test or Wilcoxon test. Reproducibility and agreement of the Londrina ADL protocol were verified using the 2-way mixed, single-measure, intraclass correlation coefficient (ICC) and Bland-Altman plots, respectively. Statistical significance was set at $P<.05$. The analysis was performed using SPSS 20.0 (SPSS, Chicago, 


\section{Londrina ADL Protocol in SubJects With COPD}

Illinois) and GraphPad Prism 6.0 (GraphPad Software, La Jolla, California).

\section{Results}

Five activities were included in the Londrina ADL protocol, including activities that involved upper limbs, lower limbs, and trunk flexion/inclination/rotation. It was also possible to include activities that could be fully and realistically performed, without pretending or simulating. Additionally, all the activities included are relatively simple to organize from the logistical point of view.

During the application of the protocol in 3 healthy young adults and 3 subjects with COPD to identify limitations in the protocol, some original characteristics of the protocol were adapted. For example, it was realized that some subjects used only one hand to perform some upper-limb activities to avoid other body movements (such as trunk movement). Therefore, for standardization purposes, we included the instruction of "moving objects with both hands." The order of the activities during the protocol was also adapted until reaching the final sequence because, in the beginning, the order of the activities was causing too much upper-limb fatigue among the subjects with COPD, leading to a need for frequent rest intervals. The final version of the Londrina ADL protocol is described below.

The protocol is composed of 5 activities and organized in stations inside a room. The room must include enough space to allow for the required distances between the stations $(6.5 \times 5.0 \mathrm{~m}$ is enough). The positions of the activity stations and the distance between them are shown in Figure 1 . The sequence of the stations is as follows.

(1) Objects on the table. The subject sits on a chair in front of a table with a drawn line separating it into 2 halves (left and right). A table of $1.2 \mathrm{~m}$ (length) $\times 0.6 \mathrm{~m}$ (width) was used, but small variations in its dimensions are allowed, since activity dynamics is preserved. The subject must have the possibility of performing not only upperlimb movements but also trunk movements. However, trunk movements are not mandatory. The subject will use his own movement dynamics. The table has 10 objects above it (4 objects of $250 \mathrm{~g}, 4$ objects of $500 \mathrm{~g}$, and 2 objects of $1 \mathrm{~kg}$ ), all together on the left half of the table. The subject takes the objects, one by one, with both hands and puts them all on the right half of the table. After that, subject returns all of the objects in the same way to the left side of the table again. There is no standardized order for object positioning. This activity was chosen to represent activities that involve upper-limb movements in the sitting position.

2) Walking with bags. The subject walks over a 6-m line, 3 consecutive times (back and forth, totaling $18 \mathrm{~m}$ ), carrying 2 bags, one in each hand. Inside the bags, there are loads representing $10 \%$ of the subject's body weight,

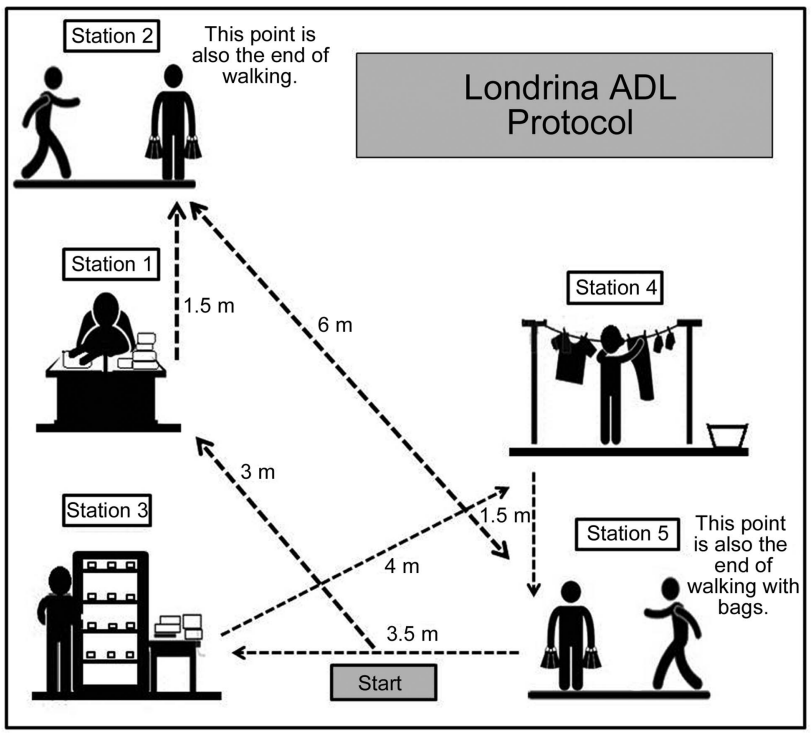

Fig. 1. Positioning of activity stations in the Londrina activities of daily living (ADL) protocol. The subject is initially positioned at the start area. He/she walks to station 1 to perform the established activity (objects on the table). Finishing activity 1 , the subject walks to station 2 (beginning of walking with bags), where he/she takes the 2 bags positioned on the floor, already containing the predetermined load, and begins walking, carrying one bag in each hand. This walking occurs in the 6-m line, 3 consecutive times. In other words, the subject walks to the end of the 6-m line, turns around, walks back to the first position, turns around, and walks once again to the end of the 6-m line, finalizing the activity on the point identified as the end of walking with bags (the same as station 5). At this point, the subject leaves the bags on the floor and walks to station 3 (shelves) to perform this activity. After this activity is concluded, the subject walks to station 4 (clothesline) and, after this activity is concluded, goes to station 5 (beginning of walking) to start walking again through the $6-\mathrm{m}$ line 3 consecutive times, this time without the bags. The protocol is finalized at the point identified as the end of walking. More details about the protocol can be found in the text.

$5 \%$ in each bag. This activity was chosen to represent activities that involve carrying loads while walking, inside the home or in the street.

3) Shelves. The subject stands in front of 4 shelves, one above the other (distributed at different levels, from a height near to knees to above the head), with a table beside them. On the table, there are 12 objects ( 4 objects of $250 \mathrm{~g}$, 4 objects of $500 \mathrm{~g}, 2$ objects of $1 \mathrm{~kg}$, and 2 objects of $2 \mathrm{~kg}$ ). The subject takes the 12 objects, one by one, with both hands and puts them on the shelves. The subject organizes the objects on the shelves in such a way that 3 objects are placed on each shelf but with no standardized positioning order regarding which object should be placed on each shelf. When all of the objects are placed on the shelves, the subject returns the objects again to the table, one by one, with both hands. This activity was chosen to represent unsupported upper-limb activities associated with trunk movement in the standing position. 


\section{Londrina ADL Protocol in SubJects With COPD}

Table 2. Subject Characteristics

\begin{tabular}{lc}
\hline \hline \multicolumn{1}{c}{ Characteristics } & Values \\
\hline Male/female sex, $n$ & $12 / 8$ \\
Age, mean $\pm \mathrm{SD} \mathrm{y}$ & $70 \pm 7$ \\
$\mathrm{BMI}$, mean $\pm \mathrm{SD} \mathrm{kg} / \mathrm{m}^{2}$ & $26 \pm 5$ \\
$\mathrm{FEV}_{1}$, mean $\pm \mathrm{SD} \%$ predicted & $54 \pm 15$ \\
$6 \mathrm{MWD}$, mean $\pm \mathrm{SD} \mathrm{m}$ & $504 \pm 83$ \\
$6 \mathrm{MWD}$, median (IQR) $\%$ predicted & $95(66-104)$ \\
$\mathrm{P}_{\mathrm{aO}_{2}}$, median $(\mathrm{IQR}) \mathrm{mm} \mathrm{Hg}$ & $76(64-80)$ \\
\hline$N=20$. & \\
$\mathrm{BMI}=$ body mass index & \\
$6 \mathrm{MWD}=6$--min walk distance & \\
$\mathrm{IQR}=$ interquartile range & \\
\end{tabular}

4) Clothesline. The subject stands in front of a clothesline, positioned at eye level. There is a bowl/basket on the ground, next to the subject, containing 10 items of clothing. Clothes should be dry and of different sizes for adults, ranging from 80 to $442 \mathrm{~g}$ (median weight of the items is $122 \mathrm{~g}$ ). Small variations in the clothes weight are allowed. Subject takes the items, one by one, with both hands and hangs them on the clothesline. After hanging all of the items, the subject returns them to inside the bowl/basket again, taking them one by one and with both hands. There is no standardized order for positioning of clothes on the clothesline or in the bowl/basket. This activity was chosen to represent unsupported upper-limb activities in the standing position, with more intense trunk movements and, eventually, squatting (movement pattern is chosen by the subject).

5) Walking. The subject walks back and forth again on the same 6-m line described in activity 2, 3 consecutive times, but without carrying the bags. This activity was chosen to represent walking in daily life.

As mentioned previously, the subject is asked to perform the activities at the usual pace in which he/she would perform them in real life. Between the activity stations, the subject also walks at the usual pace. Before the subject starts to perform the protocol, the evaluator demonstrates the activities in the order in which they will be performed, explaining how they have to be performed. The instructions given to the subject are: "Perform these activities as if you were doing them at home, in your usual day-by-day pace. You are allowed to stop to rest if you feel it is necessary. Do not worry about the order of the activities, because we will give you instructions along the protocol." After completing one activity, the subject is reminded of the next; however, no encouragement is given during the protocol.

For the criterion validity and reliability analysis, 20 subjects with COPD were included in the study. Characteristics of the participants are given in Table 2, and the values obtained from the assessment battery are shown in Table
Table 3. Values Obtained From the Assessment Battery

\begin{tabular}{|c|c|}
\hline Variables & Values \\
\hline \multicolumn{2}{|l|}{ Londrina ADL protocol } \\
\hline Duration, median (IQR) s & $378(354-426)$ \\
\hline Duration with mask, mean $\pm \mathrm{s}$ & $420 \pm 18$ \\
\hline Peak $\dot{\mathrm{V}}_{\mathrm{O}_{2}}$, mean $\pm \mathrm{mL} / \mathrm{kg} / \mathrm{min}$ & $14 \pm 2$ \\
\hline Movement intensity, mean $\pm \mathrm{m} / \mathrm{s}^{2}$ & $1.7 \pm 0.3$ \\
\hline Difficulty, median (IQR) & $3.8(1-4)$ \\
\hline Energy expenditure, median (IQR) cal & $18(14-29)$ \\
\hline Baseline $\mathrm{S}_{\mathrm{pO}_{2}}$, median (IQR) \% & $93.6(90.6-94.6)$ \\
\hline Baseline heart rate, mean \pm beats $/ \mathrm{min}$ & $84.3 \pm 10.4$ \\
\hline Baseline Borg dyspnea, median (IQR) & $0(0-1)$ \\
\hline $\begin{array}{l}\text { Baseline Borg fatigue lower limbs, median } \\
\text { (IQR) }\end{array}$ & $0(0-1)$ \\
\hline $\begin{array}{l}\text { Baseline Borg fatigue upper limbs, median } \\
\text { (IQR) }\end{array}$ & $0(0-1)$ \\
\hline Final $\mathrm{S}_{\mathrm{pO}_{2}}$, mean $\pm \%$ & $91.9 \pm 3.2$ \\
\hline Final heart rate, median (IQR) beats/min & $90.5(83.2-97.7)$ \\
\hline Final Borg dyspnea, median (IQR) & $2(0.5-3)$ \\
\hline Final Borg fatigue lower limbs, median (IQR) & $1(0-3)$ \\
\hline Final Borg fatigue upper limbs, median (IQR) & $1(0-2)$ \\
\hline \multicolumn{2}{|l|}{ Physical activity in daily life } \\
\hline Movement intensity, mean $\pm \mathrm{m} / \mathrm{s}^{2}$ & $1.6 \pm 0.3$ \\
\hline Energy expenditure, mean \pm cal & $2,034.2 \pm 456.6$ \\
\hline \multicolumn{2}{|l|}{ LCADL, median (IQR) points } \\
\hline Health care & $5(4-7.5)$ \\
\hline Domestic & $6(2.5-9.7)$ \\
\hline Physical activity & $5(3-5.7)$ \\
\hline Leisure & $3.5(3-4.7)$ \\
\hline Total & $18(16-23.7)$ \\
\hline \multicolumn{2}{|l|}{ PFSDQ-M, median (IQR) points } \\
\hline Dyspnea & $7(2.7-17)$ \\
\hline Fatigue & $5(3.2-11.7)$ \\
\hline Activities & $8(3.2-21.2)$ \\
\hline $\begin{array}{l}\text { ADL = activities of daily living } \\
\mathrm{IQR}=\text { interquartile range } \\
\text { Peak } \dot{\mathrm{V}}_{\mathrm{O}_{2}}=\text { peak oxygen consumption } \\
\mathrm{LCADL}=\text { London chest activity of daily living scale } \\
\text { PFSDQ-M = pulmonary functional status and dyspnea questionna }\end{array}$ & e, modified version \\
\hline
\end{tabular}

3. All subjects were in the registers of the research laboratory as currently involved, previously involved, or interested in being involved in a pulmonary rehabilitation program.

Results described in Table 4 concern the protocol's reliability when the subjects were not wearing the portable gas analyzer. The reliability of the Londrina ADL protocol duration is also shown in Figure 2A. There was no difference in duration between test 1 and test 2 (378 [interquartile range 354-426] vs 372 [336-420] s, $P=.10$ ). Moreover, Figure $2 \mathrm{~B}$ illustrates the reliability of the reported difficulty in the 2 protocols performed.

Even while using a gas analyzer mask, the protocol duration was reproducible (ICC $=0.97,95 \%$ CI $0.93-0.99$, $P<.001)$, presenting a quite small difference between test 
Table 4. Reliability Values of Londrina ADL Protocol Outcomes

\begin{tabular}{lccc}
\hline \hline \multicolumn{1}{c}{ Variables } & ICC & $95 \% \mathrm{CI}$ & $P$ \\
\hline Duration & 0.90 & $0.74-0.96$ & $<.001$ \\
Difficulty & 0.96 & $0.90-0.98$ & $<.001$ \\
Energy expenditure & 0.83 & $0.57-0.93$ & $<.001$ \\
Baseline $\mathrm{S}_{\mathrm{pO}_{2}}$ & 0.89 & $0.71-0.96$ & $<.001$ \\
Baseline heart rate & 0.90 & $0.74-0.96$ & $<.001$ \\
Baseline Borg dyspnea & 0.95 & $0.88-0.98$ & $<.001$ \\
Baseline Borg fatigue lower limbs & 0.95 & $0.87-0.98$ & $<.001$ \\
Baseline Borg fatigue upper limbs & 0.88 & $0.70-0.95$ & $<.001$ \\
Final $\mathrm{S}_{\mathrm{pO}_{2}}$ & 0.84 & $0.60-0.94$ & $<.001$ \\
Final heart rate & 0.86 & $0.65-0.95$ & $<.001$ \\
Final Borg dyspnea & 0.92 & $0.81-0.97$ & $<.001$ \\
Final Borg fatigue lower limbs & 0.83 & $0.56-0.93$ & $<.001$ \\
Final Borg fatigue upper limbs & 0.84 & $0.60-0.94$ & $<.001$ \\
\end{tabular}

ICC $=$ intraclass correlation coefficient

1 and test $2(420 \pm 18 \mathrm{~s}$ vs $396 \pm 18 \mathrm{~s}, P=.02)$. From the protocols performed using the portable gas analyzer, peak $\dot{\mathrm{V}}_{\mathrm{O}_{2}}$ during the protocol was obtained, and it was also shown to be reproducible (ICC $=0.89,95 \% \mathrm{CI}$ $0.53-0.98, P=.002)$. There was no difference in peak $\dot{\mathrm{V}}_{\mathrm{O}_{2}}$ between test 1 and test $2(14 \pm 0.63$ vs $\left.13 \pm 0.64 \mathrm{~mL} \cdot \mathrm{kg}^{-1} \cdot \mathrm{min}^{-1}, P=.70\right)$.

Londrina ADL protocol duration was reproducible between protocols performed with and without a mask for gas analysis, presenting ICC $=0.94,95 \%$ CI $0.85-0.98$, $P<.001$ (Fig. 2C). However, as expected, the energy expenditure and the difficulty reported by subjects showed lower reproducibility between protocols performed with and without the mask (ICC $=0.73,95 \%$ CI $0.29-0.90$, $P=.005$ and $\mathrm{ICC}=0.70,95 \%$ CI $0.21-0.88, P=.008$, respectively).

For correlation analysis, the first protocol performance without the gas analysis was used, since it was reproducible. The subject's movement intensity during the protocol performance was well correlated with the subject's movement intensity during locomotion in daily life $(\mathrm{r}=0.71$, $P=.001$ ) (Fig. 3). Correlations between the protocol duration and other outcomes are described in Table 5. There was no correlation between the protocol duration and lung function outcomes.

The questionnaire domain that best correlated with the difficulty reported by subjects regarding the protocol performance was fatigue from the PFSDQ-M $(r=0.53$, $P=.01$ ), but the same protocol outcome was also correlated with dyspnea and activities from the PFSDQ-M and physical activity and total score from the LCADL $(r=0.38$, $0.33,0.38$, and 0.33 , respectively, $P=.01$ for all). Reported difficulty, differently from duration, was correlated with absolute $\mathrm{FEV}_{1}(\mathrm{r}=0.43, P=.040)$ but was not
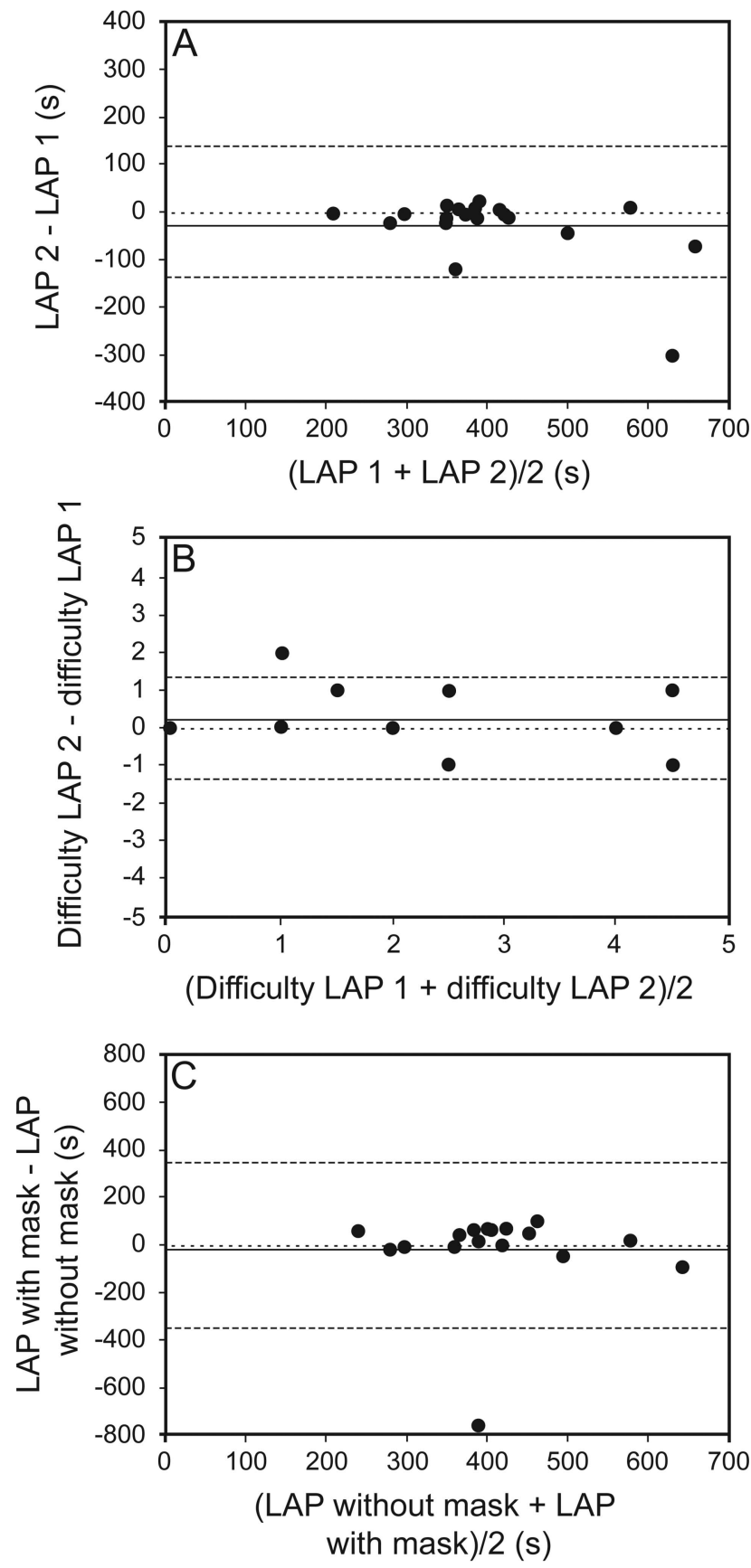

Fig. 2. Bland-Altman plots showing agreement between the Londrina activities of daily living protocol outcomes in the first and second tests. A: Londrina activities of daily living protocol (LAP) duration in the first and second tests; B: reported LAP difficulty in the first and second tests; C: LAP duration performed with and without a mask for gas analysis. The center lines show the mean difference, and the upper and lower dotted lines denote the upper and lower limits, respectively.

correlated with the walking distance in the 6MWT $(\mathrm{r}=0.12$, $P=.60)$.

Relative peak $\dot{\mathrm{V}}_{\mathrm{O}_{2}}$ achieved during the protocol performance was correlated with movement intensity $(r=0.62$, 


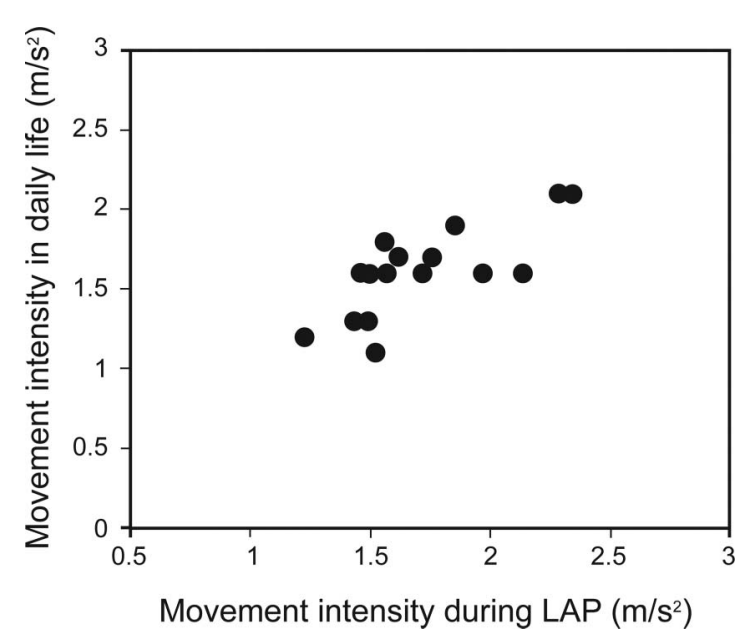

Fig. 3. Correlation between movement intensity during the Londrina activities of daily living protocol (LAP) and movement intensity during daily life (Pearson coefficient).

Table 5. Correlations With Londrina Activities of Daily Life Protocol Duration: Spearman Coefficient

\begin{tabular}{lcc}
\hline \hline \multicolumn{1}{c}{ Variables } & $\mathrm{r}$ & $P$ \\
\hline CAT & 0.41 & .041 \\
LCADL & & \\
$\quad$ Health care & 0.59 & $<.001$ \\
$\quad$ Physical activity & 0.44 & .004 \\
$\quad$ Total score & 0.48 & .031 \\
PFSDQ-M & & \\
$\quad$ Dyspnea & 0.48 & .006 \\
Fatigue & 0.36 & .02 \\
$\quad$ Activities & 0.47 & .01 \\
6MWD, \% predicted & -0.64 & \\
$\quad$ & & \\
CAT $=$ COPD assessment test & & \\
LCADL $=$ London chest activity of daily living questionnaire \\
PFSDQ-M $=$ pulmonary functional status and dyspnea questionnaire, modified version \\
6MWD $=$ 6-min walk distance
\end{tabular}

$P=.02)$ and, consequently, inversely correlated with protocol duration $(\mathrm{r}=-0.42, P=.01)$. Peak $\dot{\mathrm{V}}_{\mathrm{O}_{2}}$ was very modestly correlated with 6MWT performance $(\mathrm{r}=0.30$, $P=.01$ ). No other correlations were found with relative peak $\dot{\mathrm{V}}_{\mathrm{O}_{2}}$. Finally, there was no correlation between the energy expenditure in daily life and the energy expenditure during the protocol performance $(\mathrm{r}=-0.19, P=.40)$.

\section{Discussion}

This study presents a new protocol developed to evaluate ADL performance in subjects with COPD, the Londrina ADL protocol. It provides the possibility of having a standardized method to assess different outcomes during the performance of ADL in this population. The Londrina
ADL protocol is a reliable test, since it has shown high test-retest ICC values. This high reproducibility suggests that the protocol can be performed only once, even if a mask for gas analysis is being used to obtain further outcomes. This is a very useful finding, because studies have shown that dynamic hyperinflation plays a role in ADL performance, ${ }^{20,39}$ and for measuring dynamic hyperinflation, a mask may be necessary. The protocol has been shown not to be jeopardized by the use of a face mask. However, researchers should remember that using a mask makes the protocol more energy-consuming and difficult for subjects with COPD. Considering that mean protocol duration is around $7 \mathrm{~min}$, the whole protocol can be applied in 10-15 min (including the initial explanation for subjects). The above mentioned characteristics associated with the simplicity of the protocol, using simple objects and structure, make the protocol a feasible option for the assessment of ADL performance in subjects with COPD.

The Londrina ADL protocol is valid because there was correlation between movement intensity in daily life and movement intensity during the protocol. This indicates that it represents the subject's real life and also the subject's performance during ADL as it happens in real daily life. This was possibly achieved because the instructions given to the subjects were to perform the activities at their usual pace, as they do in their homes on a daily basis. The intensity of movement recorded by the DynaPort Move Monitor is based on acceleration. This is an interesting outcome, because walking speed is associated with survival in the elderly according to a study by Studenski et al, ${ }^{40}$ which showed that the lower the walking speed, the lower the survival in this population. ${ }^{40}$ Even with the correlation between movement intensity at home and during the protocol performance, there was no correlation between energy expenditure in these 2 situations. A hypothesis to explain these findings is that the protocol duration, for practical reasons, was substantially shorter than the duration of daily life evaluation by the motion sensors.

Moreover, the Londrina ADL protocol is correlated with widely used functional status questionnaires and even with a questionnaire that investigates disease impact on health. Although correlations between the protocol and questionnaires are moderate, these are important results. The main protocol outcome (duration) is an objective outcome, and questionnaires present subjective outcomes, since they are based on subjects' memory and feeling about their experiences in daily life. Thus, an expectation of high correlations between these instruments would not be realistic. It could be expected, therefore, that the Likert scale of difficulty for the protocol performance correlated better with the questionnaires. This was not the case, probably due to differences in design and recall period between instruments. 


\section{Londrina ADL Protocol in Subjects With COPD}

Although the Londrina ADL protocol was correlated with the 6MWT, an important outcome to characterize functional capacity, this correlation was less intense in comparison with other ADL protocols available in the literature. ${ }^{11}$ The Glittre ADL test is highly correlated with the 6MWT, possibly because of the test design, which stimulates subjects to walk as fast as possible (the instruction given to patients for the 6MWT is to walk as far as possible in $6 \mathrm{~min}$ ). Taking into account that the 6MWT represents the functional exercise capacity ${ }^{38}$ and the Londrina ADL protocol represents functional performance, a high correlation between these tests was not expected, since they investigate different concepts. ${ }^{41}$ The results also suggest that the Londrina ADL protocol is more representative of ADL performance than the above mentioned tests. According to Kocks et al, ${ }^{42}$ an indication of the limitations that patients experience in daily life (functional performance) can be more informative for clinical management than functional capacity alone, both composing the functional status concept. The functional capacity is defined as "one's maximum potential to perform activities." On the other hand, functional performance is "the physical, psychological, social, occupational and spiritual activities people actually do in the normal course of their lives to meet basic needs." 41

There are several studies in the literature that aimed at investigating outcomes derived from ADL. ${ }^{16-22}$ To accomplish this goal, authors commonly create ADL protocols specifically for their studies. However, almost all of these protocols did not have their psychometric properties evaluated. Therefore, it is not possible to affirm that they represent subjects' real ADL performance. Another problem is that each study having its own protocol hinders comparisons between studies. By developing and describing the Londrina ADL protocol's psychometric properties, we expect to provide a valid, standardized, simple, and useful tool to be used in clinical studies, without the limitations of other protocols (ie, little involvement of the upper limbs, ADL performed at the maximum and not the usual speed, and predetermined limitation of the performance).

Besides the relatively small sample size appearing to represent a more fit group of subjects, a limitation of the present study is that an accepted standard method for the analysis of the Londrina ADL protocol validity was not used. However, to the best of our knowledge, an accepted standard measure for ADL performance does not exist. Therefore, the option was to use an activity monitor to objectively detect whether subjects performed ADL in the new laboratory-based protocol at the same intensity with which they performed their ADL at home. In addition, questionnaires that are widely known as providing an evaluation of functional status related to ADL performance were also used in the analysis.

\section{Conclusions}

The Londrina ADL protocol is a simple, valid, and reliable protocol to evaluate ADL performance in subjects with COPD. It is a protocol that can be used in clinical practice and in future studies to investigate ADL outcomes, including those studies that require gas analysis and the wearing of a mask. Future studies are welcome to investigate the Londrina ADL protocol's responsiveness to interventions, reference values, and minimal important difference.

\section{REFERENCES}

1. Restrick LJ, Paul EA, Braid GM, Cullinan P, Moore-Gillon J, Wedzicha JA. Assessment and follow up of patients prescribed long term oxygen treatment. Thorax 1993;48(7):708-713.

2. Global Initiative for Chronic Obstructive Lung Disease. Global strategy for the diagnosis, management, and prevention of chronic obstructive pulmonary disease. Updated 2015. www.goldcopd.org. Accessed October 13, 2015.

3. Folgering $\mathrm{H}$, von Herwaarden $\mathrm{C}$. Exercise limitations in patients with pulmonary diseases. Int J Sports Med 1994;15(3):107-111.

4. Polkey MI, Moxham J. Attacking the disease spiral in chronic obstructive pulmonary disease. Clin Med 2006;6(2):190-196.

5. Reardon JZ, Lareau SC, ZuWallack R. Functional status and quality of life in chronic obstructive pulmonary disease. Am J Med 2006; 119(10 Suppl 1):32-37.

6. Lareau SC, Breslin EH, Meek PM. Functional status instruments: outcome measure in the evaluation of patients with chronic obstructive pulmonary disease. Heart Lung 1996;25(3):212-224.

7. Lareau SC, Meek PM, Roos PJ. Development and testing of the modified version of the pulmonary functional status and dyspnea questionnaire (PFSDQ-M). Heart Lung 1998;27(3):159-168.

8. Kovelis D, Segretti NO, Probst VS, Lareau SC, Brunetto AF, Pitta F. Validation of the Modified Pulmonary Functional Status and Dyspnea Questionnaire and the Medical Research Council scale for use in Brazilian patients with chronic obstructive pulmonary disease. J Bras Pneumol 2008;34(12):1008-1018.

9. Garrod R, Bestall JC, Paul EA, Wedzicha JA, Jones PW. Development and validation of a standardized measure of activity of daily living in patients with severe COPD: the London chest activity of daily living scale (LCADL). Respir Med 2000;94(6):589-596.

10. Pitta F, Probst VS, Kovelis D, Segretti NO, Mt Leoni A, Garrod R, Brunetto AF. [Validation of the Portuguese version of the London Chest Activity of Daily Living Scale (LCADL) in chronic obstructive pulmonary disease patients]. Rev Port Pneumol 2008;14(1):2747.

11. Skumlien S, Hagelund T, Bjørtuft O, Ryg MS. A field test of functional status as performance of activities of daily living in COPD patients. Respir Med 2006;100(2):316-323.

12. Meijer K, Annegarn J, Lima Passos V, Savelberg HH, Schols AM, Wouters EF, Spruit MA. Characteristics of daily arm activities in patients with COPD. Eur Respir J 2014;43(6):1631-1641.

13. Karloh M, Karsten M, Pissaia FV, de Araujo CL, Mayer AF. Physiological responses to the Glittre-ADL test in patients with chronic obstructive pulmonary disease. J Rehabil Med 2014;46(1):88-94.

14. Casas A, Vilaro J, Rabinovich R, Mayer A, Barberà JA, RodriguezRoisin R, Roca J. Encouraged 6-min walking test indicates maximum sustainable exercise in COPD patients. Chest 2005;128(1):5561. 


\section{Londrina ADL Protocol in Subjects With COPD}

15. Fong KNK, Ng BHB, Chow KKY, Chan PLC, Chin AMH, Chen WNK, et al. Reliability and validity of the monitored functional task evaluation (MFTE) for patients with chronic obstructive pulmonary disease (COPD). Hong Kong J Occup Ther 2001;11(1):10-17.

16. Silva CS, Nogueira FR, Porto EF, Gazzotti MR, Nascimento OA, Camelier A, Jardim JR. Dynamic hyperinflation during activities of daily living in COPD patients. Chron Respir Dis 2015;12(3):189196.

17. Castro AA, Porto EF, Iamonti VC, de Souza GF, Nascimento OA, Jardim JR. Oxygen and ventilatory output during several activities of daily living performed by COPD patients stratified according to disease severity. PLoS One 2013;8(11):e79727.

18. Lahaije AJ, van Helvoort HA, Dekhuijzen PN, Vercoulen JH, Heijdra YF. Resting and ADL-induced dynamic hyperinflation explain physical inactivity in COPD better than $\mathrm{FEV}_{1}$. Respir Med 2013; 107(6):834-840.

19. Sant'Anna T, Escobar VC, Fontana AD, Camillo CA, Hernandes NA, Pitta F. Evaluation of a new motion sensor in patients with chronic obstructive pulmonary disease. Arch Phys Med Rehabil 2012; 93(12):2319-2325.

20. Hannink JD, van Helvoort HA, Dekhuijzen PN, Heijdra YF. Dynamic hyperinflation during daily activities: does COPD global initiative for chronic obstructive lung disease stage matter? Chest 2010; 137(5):1116-1121.

21. Velloso M, Stella SG, Cendon S, Silva AC, Jardim JR. Metabolic and ventilatory parameters of four activities of daily living accomplished with arms in COPD patients. Chest 2003;123(4):1047-1053.

22. Cavalheri V, Donária L, Ferreira T, Finatti M, Camillo CA, Cipulo Ramos EM, Pitta F. Energy expenditure during daily activities as measured by two motion sensors in patients with COPD. Respir Med 2011;105(6):922-929.

23. Hill CJ, Denehy L, Holland AE, McDonald CF. Measurement of functional activity in chronic obstructive pulmonary disease: the grocery shelving task. J Cardiopulm Rehabil Prev 2008;28(6):402-409.

24. Lahaije AJ, van Helvoort HA, Dekhuijzen PN, Heijdra YF. Physiologic limitations during daily life activities in COPD patients. Respir Med 2010;104(8):1152-1159.

25. Pessoa IM, Costa D, Velloso M, Mancuzo E, Reis MA, Parreira VF. Effects of noninvasive ventilation on dynamic hiperinflation of patients with COPD during activities of daily living with upper limbs. Rev Bras Fisioter 2012;16(1):61-67.

26. Vaes AW, Wouters EF, Franssen FM, Uszko-Lencer NH, Stakenborg $\mathrm{KH}$, Westra $\mathrm{M}$, et al. Task-related oxygen uptake during domestic activities of daily life in patients with COPD and healthy elderly subjects. Chest 2011;140(4):970-979.

27. Castro AA, Kümpel C, Rangueri RC, Oliveira MD, Dornelles RA, Brito ER, et al. Daily activities are sufficient to induce dynamic pulmonary hyperinflation and dyspnea in chronic obstructive pulmonary disease patients. Clinics 2012;67(4):319-325.
28. Velloso M, do Nascimento NH, Gazzotti MR, Jardim JR. Evaluation of effects of shoulder girdle training on strength and performance of activities of daily living in patients with chronic obstructive pulmonary disease. Int J Chron Obstruct Pulmon Dis 2013;8:187-192.

29. Rutten EP, Lenaerts K, Buurman WA, Wouters EF. Disturbed intestinal integrity in patients with COPD: effects of activities of daily living. Chest 2014;145(2):245-52.

30. Barusso MS, Gianjoppe-Santos J, Basso-Vanelli RP, Regueiro EM, Panin JC, Di Lorenzo VA. Limitation of activities of daily living and quality of life based on COPD combined classification. Respir Care 2015;60(3):388-398.

31. Miller MR, Hankinson J, Brusasco V, Burgos F, Casaburi R, Coates A, et al. Standardization of spirometry. Eur Respir J 2005;26(2):319338.

32. Pereira CA, Sato T, Rodrigues SC. New reference values for forced spirometry in white adults in Brazil. J Bras Pneumol 2007;33(4): 397-406.

33. Jones PW, Harding G, Berry P, Wiklund I, Chen WH, Kline Leidy $\mathrm{N}$. Development and first validation of the COPD assessment test. Eur Respir J 2009;34(3):648-654.

34. Borg GA. Psychophysical bases of perceived exertion. Med Sci Sports Exerc 1982;14(5):377-381.

35. Salier Eriksson J, Rosdahl H, Schantz P. Validity of the Oxycon Mobile metabolic system under field measuring conditions. Eur J Appl Physiol 2012;112(1):345-355.

36. Hill K, Dolmage TE, Woon L, Goldstein R, Brooks D. Measurement properties of the SenseWear armband in adults with chronic obstructive pulmonary disease. Thorax 2010;65(6):486-491.

37. Langer D, Gosselink R, Sena R, Burtin C, Decramer M, Troosters T. Validation of two activity monitors in patients with COPD. Thorax 2009;64(7):641-642.

38. Holland AE, Spruit MA, Troosters T, Puhan MA, Pepin V, Saey D, et al. An official European Respiratory Society/American Thoracic Society technical standard: field walking tests in chronic respiratory disease. Eur Respir J 2014;44(6):1428-1446.

39. Garcia-Rio F, Lores V, Mediano O, Rojo B, Hernanz A, LópezCollazo E, Alvarez-Sala R. Daily physical activity in patients with chronic obstructive pulmonary disease is mainly associated with dynamic hyperinflation. Am J Respir Crit Care Med 2009;180(6):506512.

40. Studenski S, Perera S, Patel K, Rosano C, Faulkner K, Inzitari M, et al. Gait speed and survival in older adults. JAMA 2011;305(1): 50-58.

41. Leidy NK. Functional status and the forward progress of merry-gorounds: toward a coherent analytical framework. Nurs Res 1994; 43(4):196-202

42. Kocks JW, Asijee GM, Tsiligianni IG, Kerstjens HA, van der Molen T. Functional status measurement in COPD: a review of available methods and their feasibility in primary care. Prim Care Respir J 2011;20(3):269-275.

This article is approved for Continuing Respiratory Care Education credit. For information and to obtain your CRCE

(free to AARC members) visit www.rcjournal.com

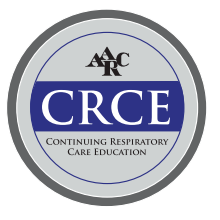

